\title{
Rac1 Controls Schwann Cell Myelination through cAMP and NF2/merlin
}

\author{
Li Guo, Chandra Moon, Karen Niehaus, Yi Zheng, and Nancy Ratner \\ Division of Experimental Hematology and Cancer Biology, Cincinnati Children's Hospital, Cincinnati, Ohio 45229
}

During peripheral nervous system development, Schwann cells (SCs) surrounding single large axons differentiate into myelinating SCs. Previous studies implicate RhoGTPases in SC myelination, but the mechanisms involved in RhoGTPase regulation of SC myelination are unknown. Here, we show that SC myelination is arrested in Racl conditional knock-out (Rac1-CKO) mice. Rac1 knock-out abrogated phosphorylation of the effector p21-activated kinase and decreased NF2/merlin phosphorylation. Mutation of NF2/merlin rescued the myelin deficit in Rac1-CKO mice in vivo and the shortened processes in cultured Rac1-CKO SCs in vitro. Mechanistically, cAMP levels and E-cadherin expression were decreased in the absence of Rac1, and both were restored by mutation of NF2/merlin. Reduced cAMP is a cause of the myelin deficiency in Rac1-CKO mice, because elevation of cAMP by rolipram in Rac1-CKO mice in vivo allowed myelin formation. Thus, NF2/merlin and cAMP function downstream of Rac1 signaling in SC myelination, and cAMP levels control Rac1regulated SC myelination.

\section{Introduction}

Schwann cells (SCs) ensheath single large-diameter axons to form myelin sheaths in the peripheral nervous system (Jessen and Mirsky 2005). These myelinating SCs electrically insulate axons for rapid impulse conduction (Jessen and Mirsky 2005; Bhatheja and Field 2006). Transcription factors necessary for myelination have been identified, and intracellular signaling pathways controlling SC myelination are being intensively analyzed. Several studies implicate the Rho family GTPase Rac1 in SC functions. Specifically, Racl is important for neurotrophin regulated SC migration (Yamauchi et al., 2005), and Rac1 mediates initial SCaxon interaction (Nakai et al., 2006). Racl has also been implicated in proper radial sorting and myelination (Benninger et al., 2007; Nodari et al., 2007). Downstream effectors of Rac1 in SC differentiation are unknown.

One protein implicated both upstream and downstream of Rac1 signaling is NF2/merlin, the product of the neurofibromatosis type 2 gene. NF2/merlin is a tumor suppressor, and NF2/merlin mutation or loss predisposes to SC tumors (Curto and McClatchey, 2008; Roche et al., 2008; Scoles, 2008). NF2/merlin is phosphorylated on serine 518 by $\mathrm{p} 21$-activated kinase (PAK), a downstream effector of Rac1. This phosphorylation alters NF2/ merlin conformation and interactions with binding partners (Rong et al., 2004; Ye, 2007). NF2/merlin also regulates Rac1 signaling, so that NF2/merlin null fibroblasts and NF2/merlin

\footnotetext{
Received May 21, 2012; revised Sept. 19, 2012; accepted Sept. 26, 2012.

Author contributions: L.G., Y.Z., and N.R. designed research; L.G., C.M., and K.N. performed research; L.G. analyzed data; L.G. and N.R. wrote the paper.

This study was supported by National Institutes of Health Grant R01CA118032 (N.R. and Y.Z.). We thank Georgianne Ciraolo for assistance with electron microscopy, Dr. Marco Giovannini for providing NF2-delta2,3 (NF2-del) mice, and Dr. Robert Hennigan for helpful discussions.

Correspondence should be addressed to Nancy Ratner, 3333 Burnet Avenue, ML 7013, Cincinnati Children's Hospital Medical Center, Cincinnati, $0 \mathrm{H}$ 45229. E-mail: Nancy.Ratner@cchmc.org.

DOI:10.1523/JNEUROSCI.2461-12.2012

Copyright $\odot 2012$ the authors $\quad 0270-6474 / 12 / 3217251-11 \$ 15.00 / 0$
}

mutant schwannoma cells exhibit membrane ruffling, characteristic of elevated active Rac1 (Kaempchen et al., 2003; Yi et al., 2008; Flaiz et al., 2009). On a cellular level, NF2/merlin stabilizes the bipolar morphology of SCs through inhibition of Rac1 (Thaxton et al., 2011). Specific pathways in which NF2/ merlin acts related to SC biology and pathology remain undefined.

NF2/merlin can stabilize cadherin-containing adherens junctions (Lallemand et al., 2003). Expression of cadherins in SCs is under developmental control (Fannon et al., 1995; Menichella et al., 2001; Wanner et al., 2006). E-cadherin maintains the structural integrity of noncompact myelin domains in vivo (Young et al., 2002; Perrin-Tricaud et al., 2007). cAMP regulates E-cadherin in postnatal SCs (Crawford et al., 2008). Notably, cAMP can act downstream of Rac1 in mouse embryonic fibroblast cells (Chen et al., 2008), and cAMP is critical for SC myelination (Monk et al., 2009; Arthur-Farraj et al., 2011).

Here we studied SC myelination in Racl conditional knockout (Rac1-CKO) mice to identify Rac1-related targets in SC differentiation. First, we showed that SC myelination was arrested in Rac1-CKO mice and that Rac1 knock-out abrogated phosphorylation of PAK and decreased NF2/merlin phosphorylation. We further generated Rac1-CKO\&NF2-del mice and showed that mutation of NF2/merlin rescued the myelin deficit in Rac1-CKO mice in vivo and shortened processes in Rac1-CKO SCs in vitro. Second, we showed that cAMP levels and E-cadherin expression decreased in Rac1-CKO mice, and each was restored by mutation of NF2/merlin. We further confirmed that reduced cAMP is one cause of the myelin deficits in Rac1-CKO mice, because these defects were rescued via rolipram elevation of cAMP in vivo. Thus, our observations define a novel pathway through which Rac1 regulates SC differentiation via NF2/merlin and cAMP signaling. The results establish a functional link between NF2/merlin, cAMP and Racl in SC myelination. 


\section{Materials and Methods}

Generation of DhhCre directed conditional Racl knock-out and Rac1CKO\&NF2-del double mutant mice. Rac flox/flox (Guo et al., 2008) were bred to DhhCre mice (Jaegle et al., 2003) to obtain DhhCre+; Racf flox/flox (Rac1-CKO) mice. Littermate DhhCre-;Rac flox/WT mice were used as controls. The genotypes of desert hedgehog (Dhh) and Racl alleles for all of the mice in our experiments were analyzed by PCR as described previously (Yang et al., 2006, 2007; Guo et al., 2008; Williams et al., 2008; Wu et al., 2008). The primers for Dhh included the following: sense, 5'-ACCCTGTTACGTATAGCCGA-3'; and antisense, $5^{\prime}$ CTCGGTATTAAACTCCAG-3'. The primers for Rac1 included the following: sense, 5' -TCCAATCTGTGCTGCCCATC-3'; and antisense, 5' GATGCTTCTAGGGGTGAGCC-3'. Primer $5^{\prime}$-CAG AGC TCG AAT CCA GAA ACT AGT A-3' was used to identify the Racl knock-out band. NF2-del mice are transgenic mice (P0-SCH- $\Delta 39-121)$ expressing a mutant NF2/merlin, in which exons 2 and 3 (amino acids 39-121) are deleted from the genomic sequence, mimicking a human mutation (Giovannini et al., 1999). This NF2/merlin mutant allele is expressed under the control of an SC-specific $\mathrm{P} 0$ promoter. These mice were crossbred with Rac1 knock-out mice to generate DhhCre+;Rac $f^{\text {flox/flox }}$;NF2del (Rac1-CKO\&NF2-del) crosses. Littermate Dhh-Cre-;Ract flox/WT; NF2-wt or Dhh-Cre-;NF2-wt genotype mice were used as controls. Dhh-Cre mice were maintained on the C57BL/6NHsd background. Rac1 ${ }^{\text {flox } /}$ flox mice were maintained on a mixed $129 \mathrm{X} 1 / \mathrm{S} v \mathrm{~J}$ and C57BL/6NHsd background. NF2-del mice were maintained on the FVB/NJ background. All animal experiments were conducted in mixed-gender mice.

Electron microscopy. Mice were anesthetized and then perfused and fixed with electron microscopy (EM) fixation solution (3\% paraformaldehyde and 3\% glutaraldehyde in PBS, pH 7.4). Sciatic nerves of wildtype and mutant mice at ages designated in the text were dissected, postfixed, osmicated, embedded, and sectioned. High-magnification pictures of ultrathin sections were taken by a Hitachi H-7600 transmission electron microscope after staining with lead citrate and uranyl acetate.

Western blots. Sciatic nerve tissue was homogenized using a TissueRuptor (Qiagen) and lysed in lysis buffer $\left(20 \mathrm{~mm} \mathrm{NaPO}_{4}, 150 \mathrm{~mm}\right.$ $\mathrm{NaCl}, 2 \mathrm{mM} \mathrm{MgCl}_{2}, 0.1 \%$ Nonidet P-40, 10\% glycerol, $10 \mathrm{~mm}$ sodium fluoride, $0.1 \mathrm{~mm}$ sodium orthovanadate, $10 \mathrm{~mm}$ sodium pyrophosphate, $10 \mathrm{~nm}$ okadaic acid, $1 \mathrm{~mm}$ dithiothreitol, $10 \mu \mathrm{g} / \mathrm{ml}$ leupeptin, $10 \mu \mathrm{g} / \mathrm{ml}$ aprotinin, $10 \mu \mathrm{g} / \mathrm{ml}$ pepstatin, $10 \mu \mathrm{g} / \mathrm{ml}$ tosyl-L-phenylalanine chloromethyl ketone, and $10 \mu \mathrm{g} / \mathrm{ml}^{\alpha}$-tosyl-L-lysine chloromethyl ketone). Homogenates were centrifuged at $10,000 \times g$ for $10 \mathrm{~min}$, and protein extract supernatants were collected. Protein concentration was measured on a spectrophotometer using Bio-Rad DC Protein Assay Kit. Equal amounts of protein were fractionated by $4-20 \%$ SDS-PAGE (NuStep) and transferred to PVDF membrane. Membranes were incubated with primary antibodies, followed by appropriate secondary antibodies, and developed by GE Healthcare ECL Detection Reagents. The following primary antibodies were used: Rac1 (1:800; BD Transduction Laboratories), P-Erk1/2 (1:2000; Cell Signaling Technology), P-merlin (1:500; Abcam), merlin (1: 800; Abcam), P-PAK1/2 (1:1000; Cell Signaling Technology), PAK (1:1000; Cell Signaling Technology), Erk1/2 (1:1000; Cell Signaling Technology), E-cadherin (1:1000; Cell Signaling Technology), neurofilament (1:1000; Abcam), Pmp22 (1:5000; Abcam), and $\beta$-actin (1:10,000; Cell Signaling Technology). Anti-rabbit and anti-mouse HRP-conjugated secondary antibodies (1:5000) were purchased from Bio-Rad.

Immunofluorescence. Mice were killed and perfused with $4 \%$ paraformaldehyde (PFA), and sciatic nerves were dissected. Sciatic nerves were fixed in 4\% PFA overnight, incubated in $20 \%$ sucrose buffer, and then frozen in OCT compound (Sakura). Frozen blocks were cut into 6-8 $\mu \mathrm{m}$ frozen sections using a Leica Cryostat. For staining, frozen sciatic nerve sections were incubated with $4 \%$ PFA for 20 min at room temperature, washed in PBS, and permeabilized with $0.3 \%$ Triton X-100 in PBS when necessary. Sections were blocked for $1 \mathrm{~h}$ with blocking buffer (10\% serum in PBS) and incubated with primary antibody at $4^{\circ} \mathrm{C}$ overnight. The next day, sections were washed with PBS and incubated in Alexa Fluor 488- or Alexa Fluor 594-conjugated secondary antibodies (1:400; Jackson ImmunoResearch) for $1 \mathrm{~h}$ at room temperature. To visualize nuclei, sec- tions were stained with DAPI for $10 \mathrm{~min}$, washed with PBS, and mounted in FluoromountG (Electron Microscopy Sciences). Cultured SCs were immunostained with P75NTR antibody (Millipore Bioscience Research Reagents) and Alexa Fluor 549-phalloidin antibody (Invitrogen) to visualize SC protrusions and lamellipodia in vitro. A Rac-GTP antibody was used at 1:500 (NewEast Biosciences) to detect active Rac1 in cultures. All the images were acquired using a fluorescence microscope with $10 \times /$ 0.4 numerical aperture or $40 \times / 0.6$ numerical aperture objectives (Carl Zeiss). Acquisition software NIH ImageJ was used.

Cell cultures and staining. Primary mouse SC cultures were obtained from postnatal day (P) 30 sciatic nerves. In brief, sciatic nerves were sterilely dissected from killed $\mathrm{P} 30$ mice and incubated at $37^{\circ} \mathrm{C}, 7.5 \% \mathrm{CO}_{2}$ in DMEM medium (Invitrogen) supplemented with $10 \%$ fetal bovine serum (Gemini Bio-Products), $1 \%$ penicillin-streptomycin (Thermo Fisher Scientific), forskolin ( $2 \mu \mathrm{M}$; Calbiochem), and $\beta$-heregulin (HRG) ( $10 \mathrm{ng} / \mathrm{ml} ; \mathrm{R} \& \mathrm{D}$ Systems). Pretreatment medium was replaced every $2 \mathrm{~d}$. After 6-9 d, nerves were incubated in dissociation medium [Leibovitz medium (Invitrogen) containing collagenase type I $(130 \mathrm{U} / \mathrm{ml}$; Worthington Biochemicals), dispase II ( $2.5 \mathrm{mg} / \mathrm{ml}$; Roche Diagnostics), gentamycin (50 $\mu \mathrm{g} / \mathrm{ml}$; Lonza), and fungizone ( $2.5 \mu \mathrm{g} / \mathrm{ml}$; Invitrogen)] for $3 \mathrm{~h}$ at $37^{\circ} \mathrm{C}$. Cells were dissociated using a narrowed Pasteur pipette and then were centrifuged for $5 \mathrm{~min}$ at $1000 \mathrm{rpm}$. Cells were resuspended in DMEM/F-12 medium (Invitrogen) supplemented with N2 supplement solution (Invitrogen), forskolin (2 $\mu \mathrm{M}$; Calbiochem), $\beta$-HRG $(10 \mathrm{ng} / \mathrm{ml})$, gentamycin (50 $\mu \mathrm{g} / \mathrm{ml}$; Lonza), and fungizone (2.5 $\mu \mathrm{g} / \mathrm{ml}$; Invitrogen). Cells were plated on poly-L-lysine (Sigma) and laminin (BD Biosciences) coated plates and incubated at $37^{\circ} \mathrm{C}, 7.5 \% \mathrm{CO}_{2}$. Medium was changed every $3 \mathrm{~d}$, and the cells were passaged when confluent. Cells were used at passage $0-1$.

cAMP measurement and cAMP elevation. Levels of cAMP were measured and quantified using a cAMP assay kit (Enzo Life Sciences). Homogenates of sciatic nerves or lysates from cell cultures were used for the cAMP assay according to the instructions of the manufacturer. To elevate cAMP levels in cultured SCs, forskolin ( $5 \mu \mathrm{M}$; Sigma) was added into serum-free cell culture medium for $30 \mathrm{~min}$. The Racl specific inhibitor NSC 23766 (Gao et al., 2004) was used to treat cells for 30 min before adding forskolin. To elevate cAMP levels in mice in vivo, rolipram (5 $\mathrm{mg} / \mathrm{kg}$ daily; Calbiochem) was administered daily via intraperitoneal injection for 6-8 weeks.

Morphometric quantification and statistical analyses. Morphometric measurements of myelination were performed in electron micrographs. Myelin sheath thickness was quantified by $g$-ratio analysis (the ratio of the axon diameter to the myelinated fiber diameter). The diameter of the axon and the myelinated fiber were measured in the electron microscopy (EM) images of the nerve cross-sections.

A cell-counter plugin from NIH ImageJ software was used to analyze the number of one-to-one myelinated axons, nonmyelinated axons, and the axon number in each axonal bundle. The quantification of SC process number, length, and SC lamellipodia number in primary cultures was performed using NIH ImageJ software. Statistical significance was determined between two individual samples with the Student's $t$ test. For multiple comparisons, one-way ANOVA, followed by Tukey's post hoc test was used. Significance was denoted as ${ }^{*} p<0.05$, ${ }^{* *} p<0.01$, or ${ }^{* * *} p<0.001$.

\section{Results}

\section{Conditional knock-out of Rac1 in SCs in vivo}

To analyze the role of the small GTPase Racl in SCs in vivo, Rac1$\mathrm{CKO}$ mice were generated by using the Cre recombinase-LoxP recombination system under the control of Dhh gene. In these mice, Dhh activates Cre recombinase expression in SCs at embryonic day 12.5 (E12.5) (Jaegle et al., 2003). Exon1 of the Racl alleles were excised during Dhh-Cre recombination (Fig. 1A). The Racl knockout alleles were confirmed by PCR (Fig. 1B).

Conditional knock-out of Rac1 in SCs led to hindlimb dysfunction in mutant mice (Fig. 1C), which is consistent with a previous study using a different set of conditional knock-out mice (Benninger et al., 2007). Rac1-CKO mice showed tremors 
A

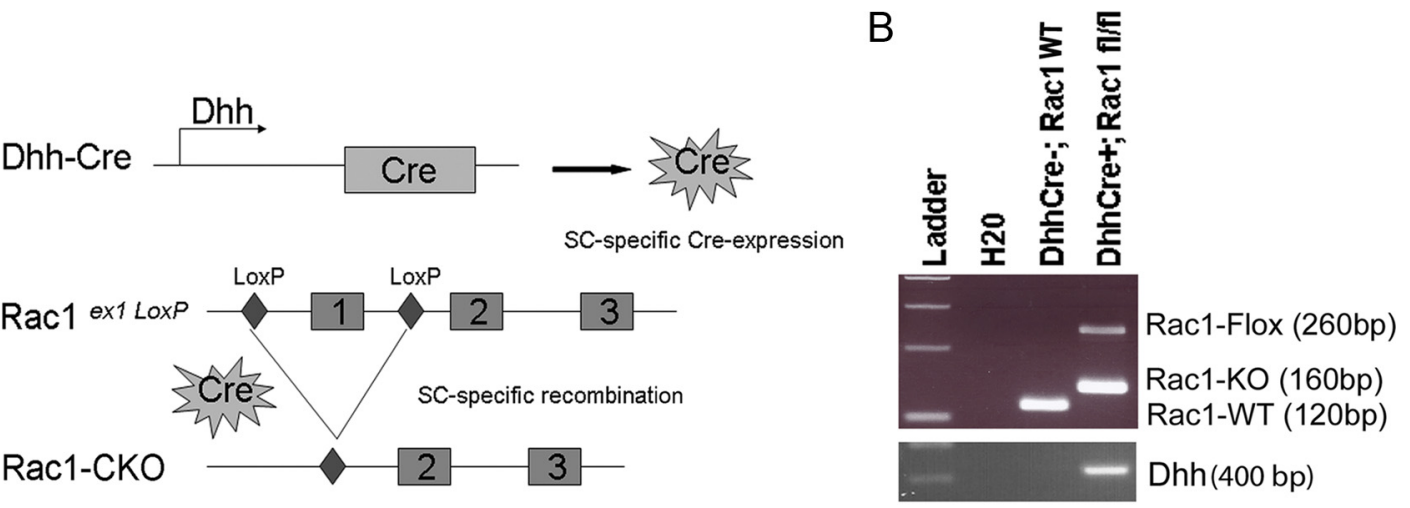

C
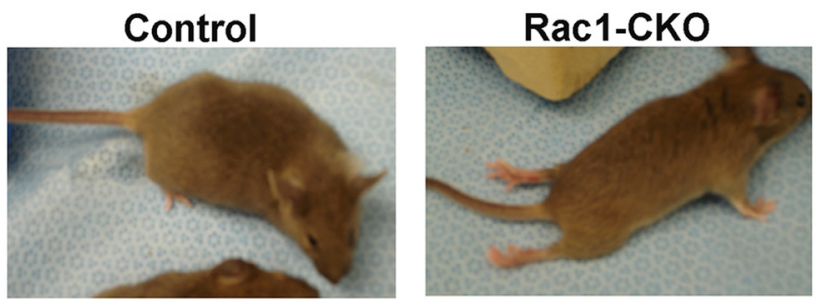

D

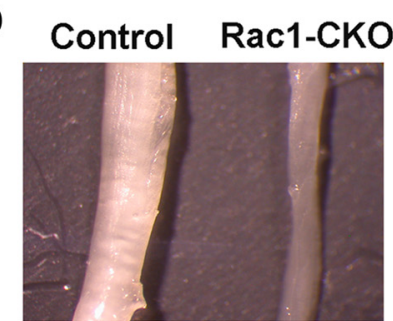

E

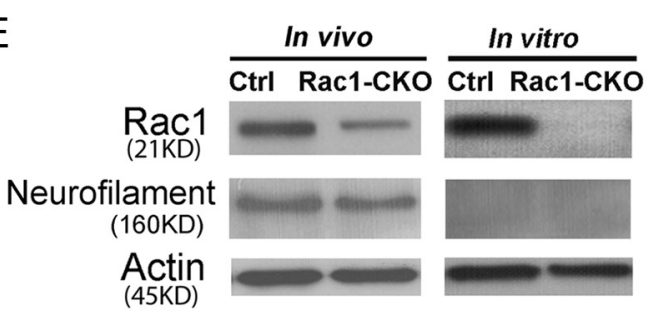

G

Control

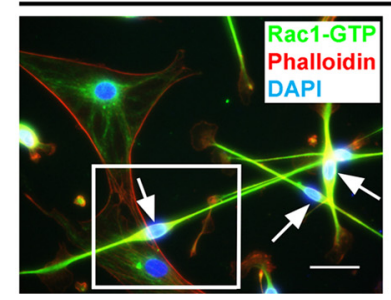

$\mathrm{F}$

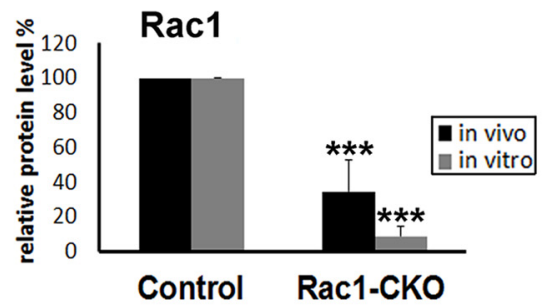

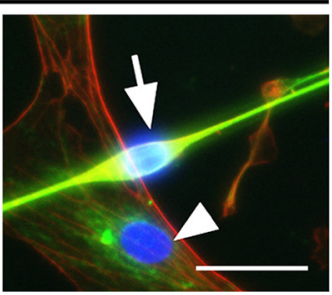

Rac1-CKO

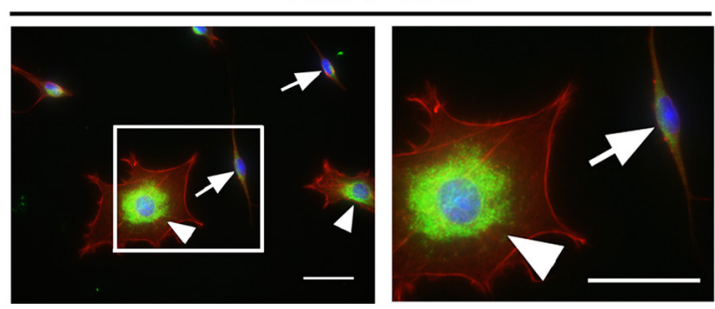

Figure 1. Generation and characterization of Rac1-CKO mice. A, DhhCre directed recombination in Rac1 mutant mice. Dhh activates Cre recombinase expression in SC from E12.5. After Cre recombination, exon 1 of the Rac1 alleles between loxP sites are excised. $\boldsymbol{B}$, Genotyping for DhhCre, Rac1-knock-out, and Rac1-flox alleles in samples of wild-type and Rac1-CK0 nerves. $C$, Control and Rac1-CKO P30 mice are shown. Hindlimb paralysis in Rac1-CKO mice is present as noted by dragging their hindlimbs. D, Sciatic nerves from P30 Rac1-CK0 and control mice are shown. Rac1-CK0 sciatic nerves are thinner than wild-type nerves. $\boldsymbol{E}$, Western blot analysis shows that Rac1 protein levels are decreased in P30 sciatic nerves of mutant mice. Residual Rac1 protein is attributed to axonal Rac1 because Rac 1 protein is nearly absent in sciatic nerves after in vitro axon degeneration, confirmed by loss of neurofilament protein. $\boldsymbol{F}$, Quantification from three independent experiments shows significant decrease of Rac1 protein in Rac1-CKO sciatic nerves. G, SCS cultured from control and Rac1-CK0 sciatic nerves were immunostained using Rac-GTP (green) and phalloidin (F-actin cytoskeleton, red) antibodies. Nuclei were visualized by DAPI (blue). GTP-bound, active forms of Rac1 are eliminated in Rac1-CKO SCs (arrow) but remained in wild-type fibroblasts (arrowhead) from Rac1-CKO nerves. ${ }^{* * *} p<0.001$ by Student's $t$ test. Error bars indicate \pm SEM. Scale bars: $G, 25 \mu \mathrm{m}$.

by $20 \mathrm{~d}$ old and progressive paralysis of their hindlimbs as the mice aged. Rac1-CKO mice displayed complete paralysis of hindlimbs by 2 month of age. Rac1-CKO mice lived for $>6$ months provided that food was easily accessible. At P30, sciatic nerves from Rac1-CKO were thinner than the sciatic nerves of wild-type mice (Fig. 1D). Reduction of Rac1 protein expression in the sciatic nerves of these mutant mice was verified by Western blot (Fig. 1E,F). There remained residual Racl protein in mutant nerves. We hypothesized that this was generated from axons in the nerve. Consistent with this hypothesis, Racl protein was barely detectable in Rac1-CKO sciatic nerve from which axons were removed by in vitro degeneration for $6 \mathrm{~d}$ (Fig. $1 E, F$ ). GTP- bound active Rac1 was also eliminated in Rac1-CKO SCs (Fig. $1 G$, arrows) as shown by immunostaining, using an antibody that detects Rac-GTP.

\section{Myelination is arrested in Rac1-CKO sciatic nerves}

To investigate the pathological changes underlying these abnormalities in Rac1-CKO mice, nerve ultrastructure in Rac1-CKO sciatic nerves was compared with control sciatic nerves by EM at different developmental stages. At P1, some axons were sorted and already thinly myelinated in control sciatic nerves, but no myelinated axons were observed in Rac1-CKO sciatic nerves (Fig. $2 A$ ). At P30, P60, and P120, large axons in control sciatic nerves 
A

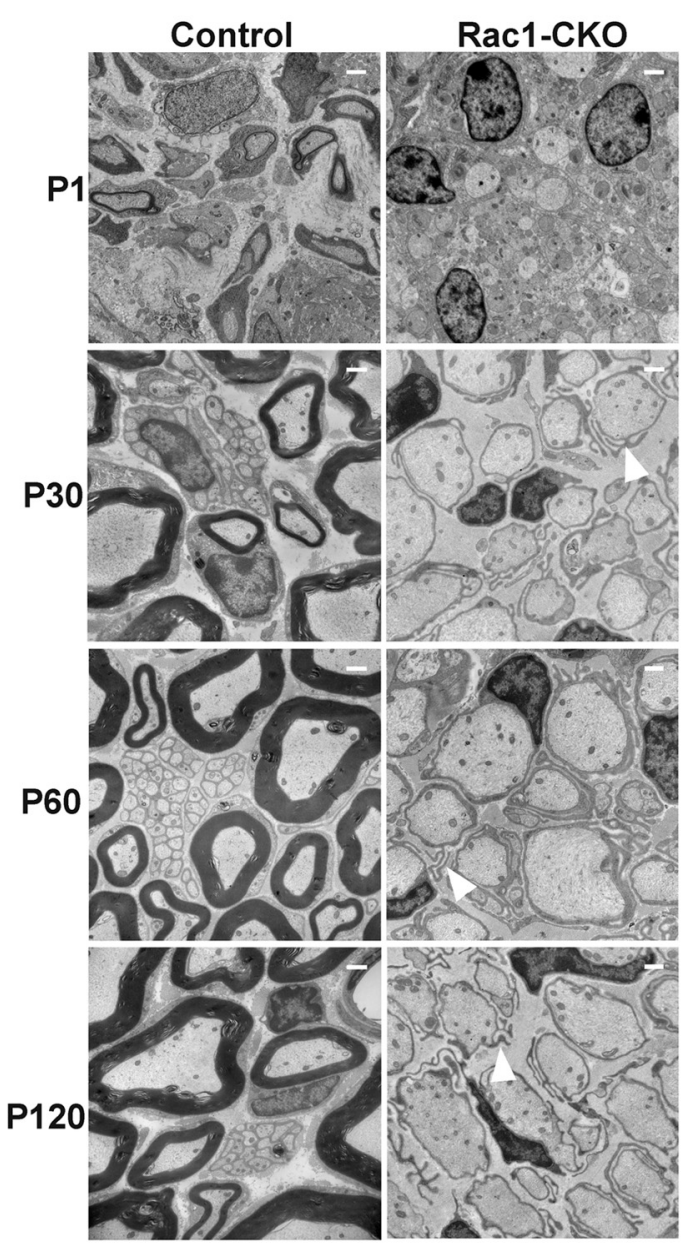

B

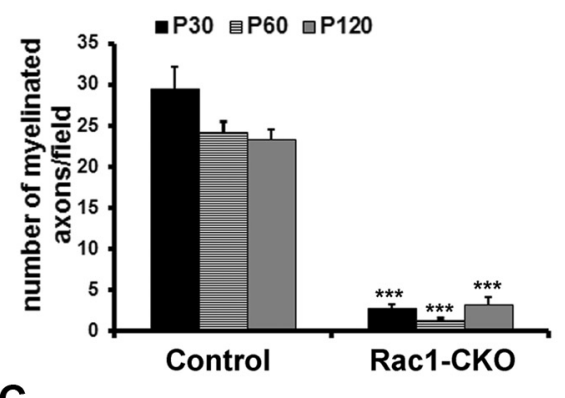

C

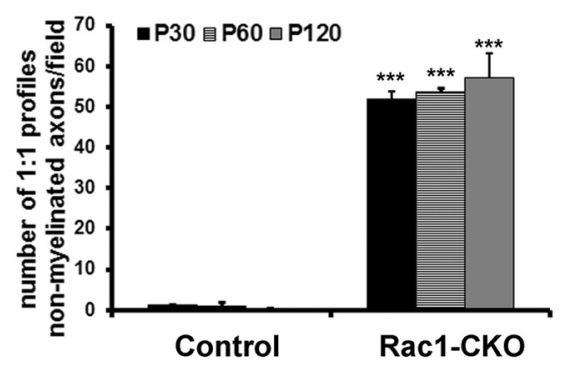

D

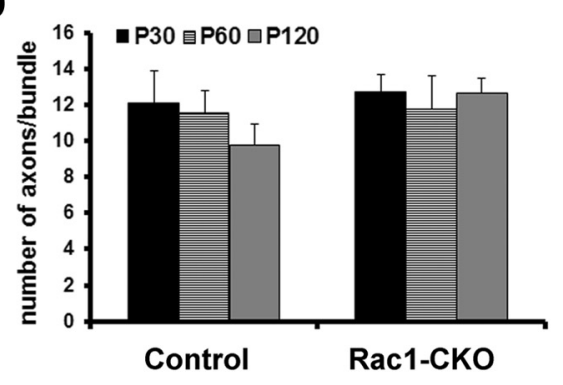

E Control Rac1-CKO

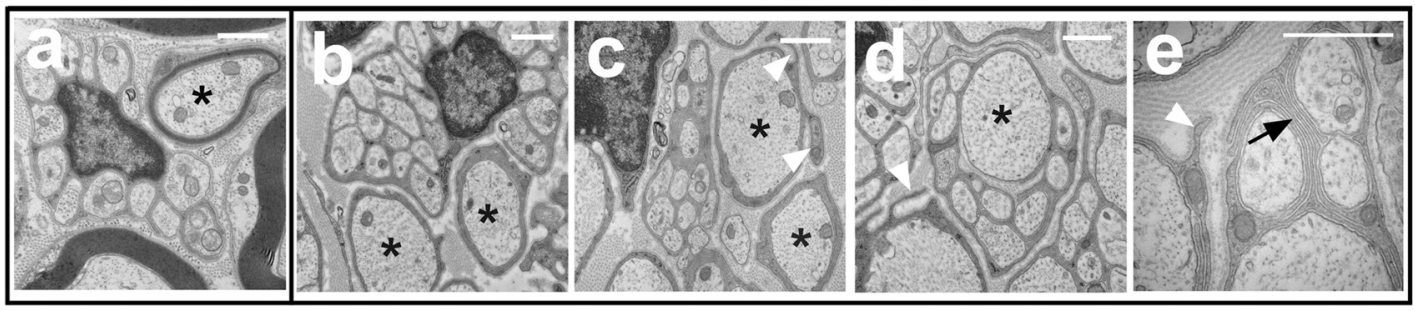

Figure 2. Myelination defects in Rac1-CK0 mice. $A$, EM analysis of control and Rac1-CK0 sciatic nerve cross-sections at P1, P30, P60, and P120. At P1, SCs begin to form a few myelin sheaths in control sciatic nerves. In contrast, no myelin sheaths are detectable in Rac1-CKO sciatic nerves. At P30, P60, and P120, SCs form myelin sheaths around large axons (myelinating SCS) in wild-type sciatic nerves. In contrast, SC myelination is essentially absent in Rac1-CKO sciatic nerves at all ages. SCs in Rac1-CKO nerves form one-to-one relationships with large axons without myelin sheath formation. Abnormal SCs protrusions (arrowheads) are found in Rac1-CKO nerves. B. There is a significant decrease in the number of myelinated axons in Rac1-CKO sciatic nerves. $\boldsymbol{C}$, There is a significant increase in the number of one-to-one SC-axon relationships without myelination in Rac1-CKO sciatic nerves. $\boldsymbol{D}$, There is no significant difference in axonal bundle size (axons/bundle) in Rac1-CKO sciatic nerves. $\boldsymbol{E}$, SC ensheathing small axons as Remak bundles are shown ( $\boldsymbol{a}$, control; $\boldsymbol{b}$ - $\boldsymbol{e}$, Rac1-CK0). SCs wrapping large axons (asterisk) form myelin sheath in wild-type nerve (a) but no myelin sheath in Rac1-CKO nerve $(\boldsymbol{b}-\boldsymbol{e})$. Abnormal SCs protrusions (arrowheads) are found in SCs in one-to-one relationships with large axons from Rac1-CKO nerves ( $\boldsymbol{c}, \boldsymbol{d})$. One large axon is not completely sorted out from axonal bundle in Rac1-CKO nerves (d). Redundant Rac1-CKOSC wraps within the axonal bundles were observed (e, arrow). For $\boldsymbol{B}-\boldsymbol{D}, n \geq 15$ fields from at least 3 animals per genotype per age were analyzed. ${ }^{*} p<0.05,{ }^{* *} p<0.01,{ }^{* * *} p<0.001$ by Student's $t$ test. Error bars indicate \pm SEM. Scale bars: $A, E, 1 \mu \mathrm{m}$.

were well myelinated. However, $<5 \%$ of axons in Rac1-CKO sciatic nerves were myelinated (Fig. $2 A, B$ ), although most SCs had differentiated to one-to-one interactions with large axons in Rac1-CKO sciatic nerves (Fig. $2 \mathrm{~A}, \mathrm{C}$ ). The vast majority of large axons in Rac1-CKO mice were sorted but unmyelinated even at P15. These results indicate that Rac1 plays a critical role in SC myelination.

A previous study reported SC axonal sorting defects in E17.5 to P24 nerves in the absence of Racl (Benninger et al., 2007).
Consistent with that study, we observed irregular membranedelineated cytoplasmic protrusions from SCs in adult Rac1-CKO mouse sciatic nerves. These protrusions from Racl-CKO SCs were primarily from SCs in one-to-one relationship with axons (Fig. 2A,E, arrowheads). Remak bundles in adult Rac1-CKO sciatic nerves contain similar numbers of small axons as control mice (Fig. 2D). The numbers of Remak bundles also did not change in the absence of Racl. We quantified aspects of axons and SCs within Remak bundles in sections from five mice. Most 
A

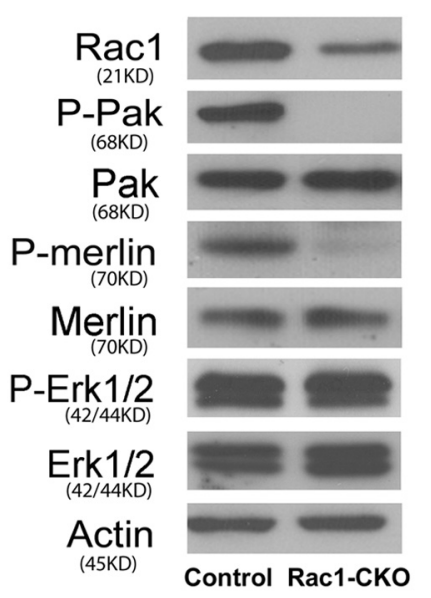

B
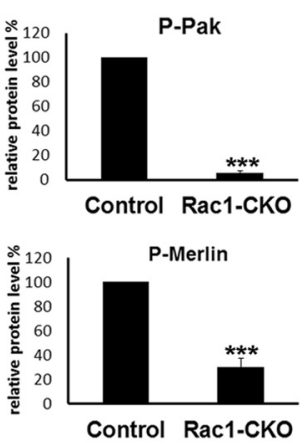

Control Rac1-CKO

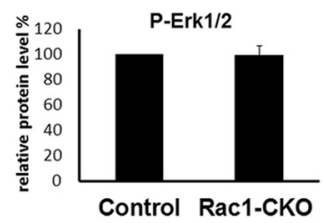

Figure 3. Decreased PAK and merlin phosphorylation in Rac1-CKO sciatic nerves. A, Western blots analysis of Rac1-CK0 sciatic nerves from P30 mice. Actin expression level is used as a protein loading control. Blots are representative of nerve protein extracts from at least four independent experiments for each genotype. $\boldsymbol{B}$, Quantification from five independent experiments shows phosphorylation of PAK (P-Pak_Thr423/Thr402) and merlin (P-merlin_Ser518) are downregulated in Rac1-CK0 sciatic nerves. Expression of P-Erk1/2, total Erk1/2, total PAK, and total merlin are not changed in Rac1-CKO sciatic nerves. ${ }^{* * *} p<0.001$ by Student's $t$ test. Error bars indicate \pm SEM.

(96 $\pm 3 \%$ ) of the unmyelinated small axons in adult Rac1-CKO sciatic nerves were normally segregated by SC processes in Remak bundles (Fig. 2E). However, some Remak bundle abnormalities were observed in Rac1-CKO nerves. For example, $2 \pm 0.8 \%$ of Remak bundles contained one or two axons with redundant SC wraps (Fig. 2Ee, black arrow). In addition, $49 \pm 6 \%$ of Remak bundles contained one to three large diameter axons $(>1 \mu \mathrm{M})$ that remained unsorted (Fig. $2 E d$ ), so that $6 \pm 2 \%$ of axons within Remak bundles were large-diameter axons. These data confirm an axonal sorting defect in Rac1-CKO nerves. Together, our data indicate that Racl is necessary for SC myelin sheath formation and plays a role in axonal sorting in SC.

Rac1 regulates $\mathrm{PAK}$ and NF2/merlin phosphorylation in vivo Next, we used Western blots to define the possible downstream effectors that mediate the myelination deficiency in Rac1-CKO sciatic nerves. Phosphorylation and activity of NF2/merlin is regulated by a Racl effector, PAK (Xiao et al., 2002; Rong et al., 2004; Ye 2007). Phosphorylation of PAK at Thr423(PAK1)/ Thr402(PAK2) and phosphorylation of merlin at Ser518 were dramatically downregulated in Racl-CKO sciatic nerves (Fig. $3 A, B)$. Expression of P-Erk1/2, total Erk1/2, total PAK, and NF2/ merlin were not changed in Rac1-CKO sciatic nerves (Fig. $3 A, B$ ). These results indicate that Rac1 regulates PAK and NF2/merlin phosphorylation in SCs in vivo. NF2/merlin phosphorylation at Ser518 changes merlin conformation and activity (Sher et al., 2012). Our data support the idea that NF2/merlin is dephosphorylated in the absence of Rac1, and the change in NF2/merlin phosphorylation may lead to the myelin deficits found in Rac1CKO mice.

\section{Myelin deficiency in Rac1-CKO mice is rescued by NF2/merlin mutant}

To test whether NF2/merlin function is critical for the absence of SC myelination in Racl-CKO mice, Racl knock-out mice were intercrossed with NF2-del transgenic mice in which exons 2 and 3 (amino acids 39-121) of NF2/merlin are deleted (Giovannini et al., 1999). This NF2/merlin mutant allele is expressed under the control of the SC-specific P0 promoter. We confirmed SC hyperplasia in NF2-del mouse nerves and observed no defects in myelin internodes at P30-P180. NF2-del transgenic mice and homozygous NF2/merlin knock-out mice (P0Cre;NF2 ${ }^{\text {flox2/flox2 }}$ ) mice have similar paranodal defects and SC hyperplasia, and both types of NF2/merlin mutants develop tumors with similar incidence and timing (Giovannini et al., 1999, 2000; Denisenko et al., 2008). Analysis of SC cultures from these two mouse strains reveals identical growth after confluence and identical gene expression (Macro Giovannini, personal communication), indicating that the NF2-del acts as a functional null allele. Strikingly, paralysis of hindlimbs in adult Rac1-CKO mice was improved in Rac1CKO\&NF2-del double mutant mice. In contrast to the thinner sciatic nerves in Rac1-CKO mice, sciatic nerves in RaclCKO\&NF2-del double mutant mice were close to the normal size of control sciatic nerves in wild-type mice (Fig. $4 A$ ). Next, we used EM to test whether SC myelination defects in Rac1-CKO mice were rescued in Rac1-CKO\&NF2-del mice. At 4 months old, a dramatic increase in myelinated axons was observed in Rac1-CKO\&NF2-del mice compared with the profound absence of myelinated axons in Rac1-CKO mice (Fig. $4 B, C$ ), indicating that NF2/merlin mutant rescues the myelination deficiency in Rac1-CKO mice. Consistent with this finding, decreased expression of the peripheral myelin protein Pmp22 in Rac1-CKO nerves was rescued in Rac1-CKO\&NF2-del nerves (Fig. 4E). The myelin sheath thickness ( $g$-ratio; ratio of axon diameter to axon + myelin sheath diameter) was calculated for myelinated axons in wild-type control and Rac1-CKO\&NF2-del mice. The $g$-ratio for Rac1-CKO\&NF2-del mice was $0.771(n=613)$ compared with $0.646(n=618)$ for control mice. Thus, myelin sheaths are present in the Rac1-CKO\&NF2-del mice but myelin is thinner than normal.

The Remak bundle defects including one or two large axons within some Remak bundles in Rac1-CKO nerves were not rescued in Rac1-CKO\&NF2-del nerves. The numbers of axons within Remak bundles also did not change in Rac1-CKO\&NF2del nerves (data not shown). Irregular SC protrusions in Rac1CKO sciatic nerves in vivo remained in Rac1-CKO\&NF2-del sciatic nerves (Fig. 4B, F, arrowheads). Effectors apart from NF2/ merlin may mediate those abnormalities.

\section{Impaired SC process elongation in Rac1-CKO SCs is rescued by an NF2/merlin mutant}

A well-known role of Rho GTPases is regulation of the cellular cytoskeleton, and previous evidence supports a role of Racl activity for SC process elongation and lamellipodia formation (Nodari et al., 2007). To test whether NF2/merlin is involved in Racl-mediated SC process elongation, we cultured primary SCs from sciatic nerves of P30 control, Rac1-CKO, NF2-del, and Rac1-CKO\&NF2-del mice. Compared with control SCs, SC process length was shorter in Rac1-CKO cultures (Fig. $5 A, B, D$ ), and lamellipodia (including both radial lamellipodia and axial lamellipodia) were essentially lost in the absence of Rac1 (Fig. $5 A, B, E$ ). Shortened SC processes in Rac1-CKO SCs were rescued by NF2/ merlin mutation (Fig. $5 A, B, D$ ), whereas the lamellipodia defects in Rac1-CKO SCs were not affected by NF2/merlin function (Fig. $5 A, B, E)$. These results confirm that Racl promotes SC process elongation and lamellipodia formation under physiological conditions. These data suggest that NF2/merlin plays a role in Rac1regulated SC process elongation, which correlates with our 
A

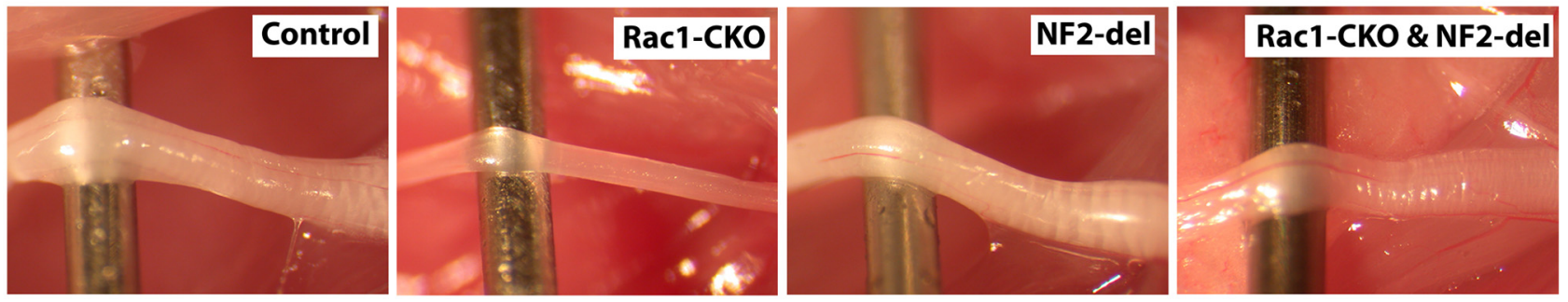

B
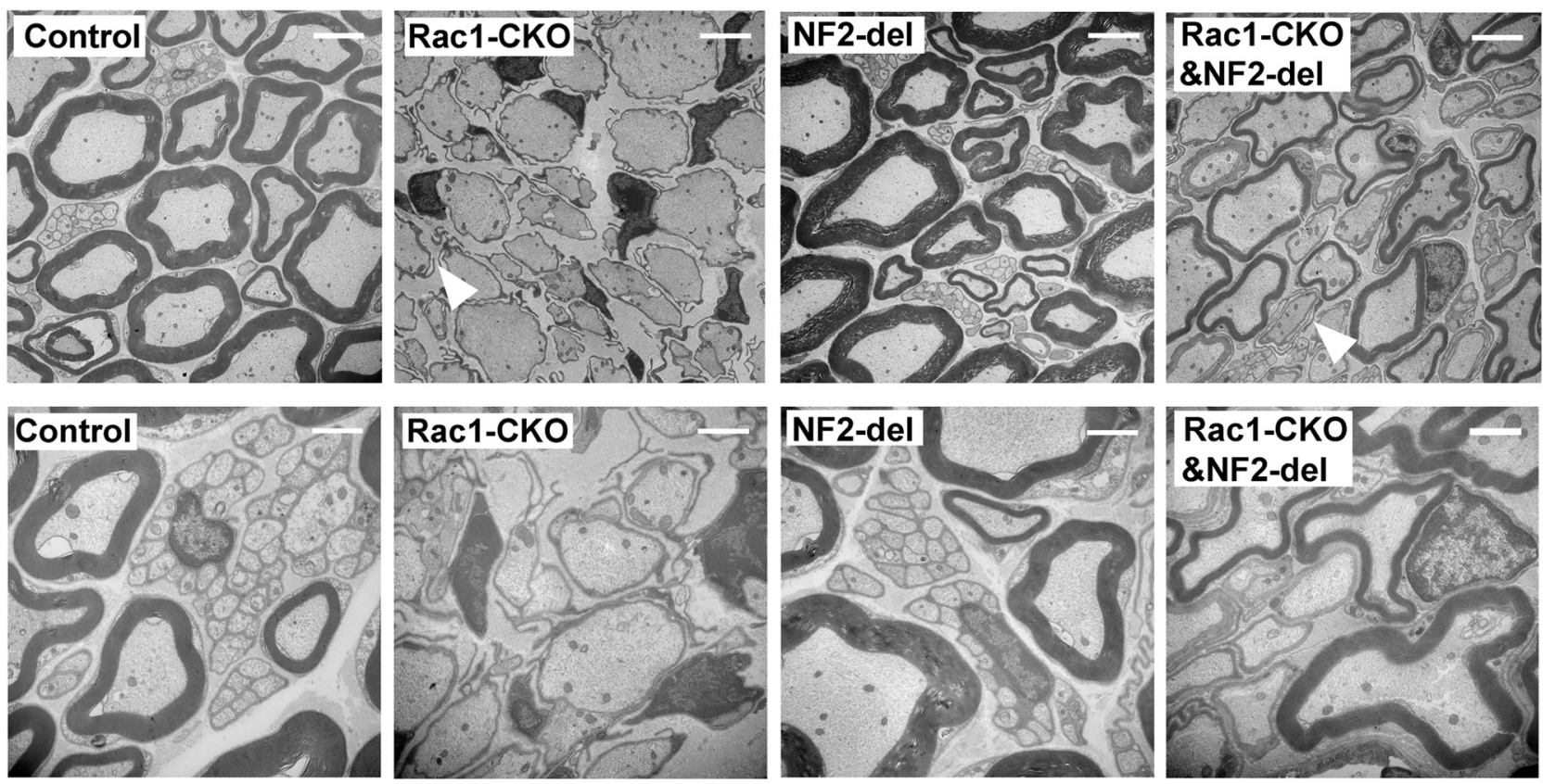

C

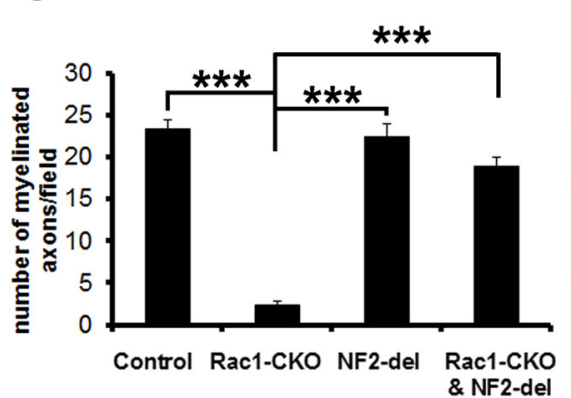

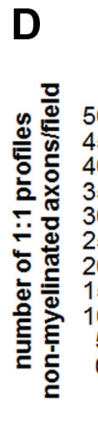

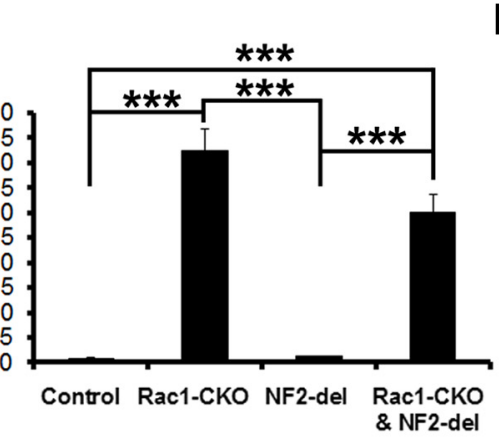

Rac1-CKO
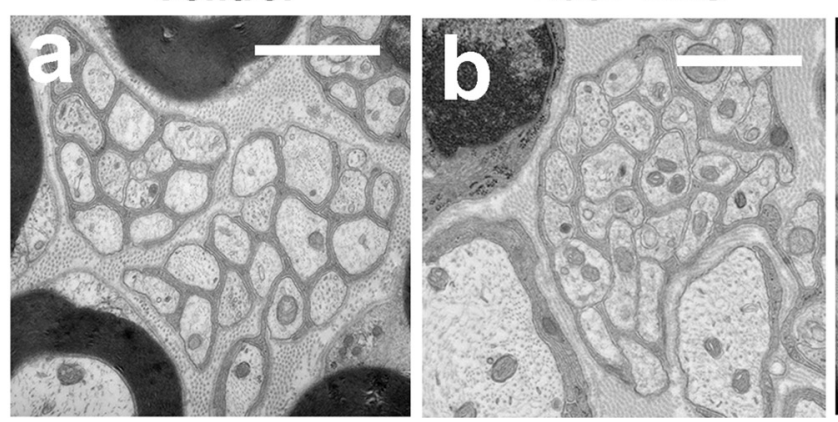

E
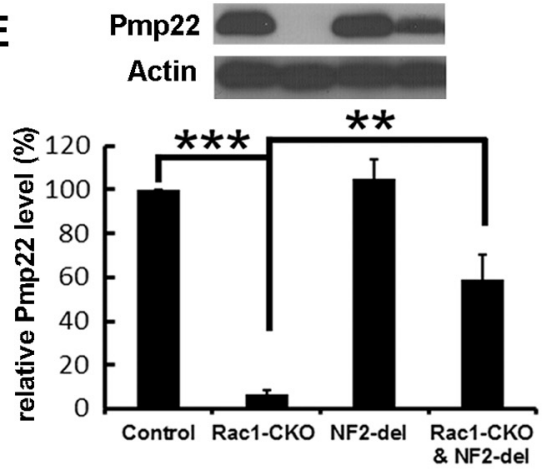

Rac1-CKO\&NF2-del
NF2-del

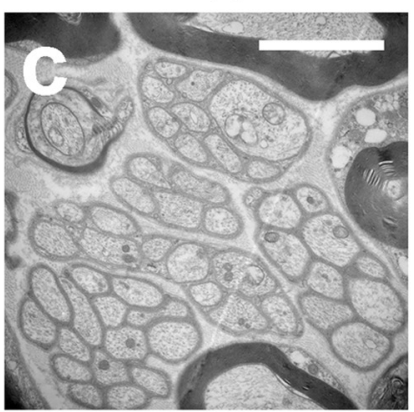

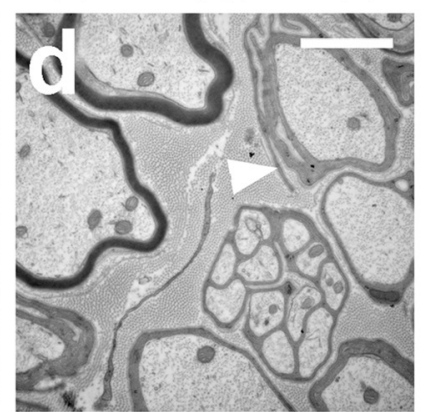

Figure 4. Myelination deficiency in Rac1-CKO mice is rescued by NF2/merlin mutation. $\boldsymbol{A}$, Sciatic nerves from 3-month-old control, Rac1-CKO, NF2-del, and Rac1-CK0\&NF2-del mice are shown. Rac1-CKO sciatic nerves are thinner than control nerves. Rac1-CKO\&NF2-del nerves are similar to the size of control nerves. $\boldsymbol{B}$, EM analysis of control, Rac1-CKO, NF2-del, and Rac1-CKO\&NF2-del sciatic nerve cross-sections at P120. More myelinated axons are present in Rac1-CK0\&NF2-del sciatic nerves than in Rac1-CKO nerves. Irregular SC protrusions (Figure legend continues.) 
A
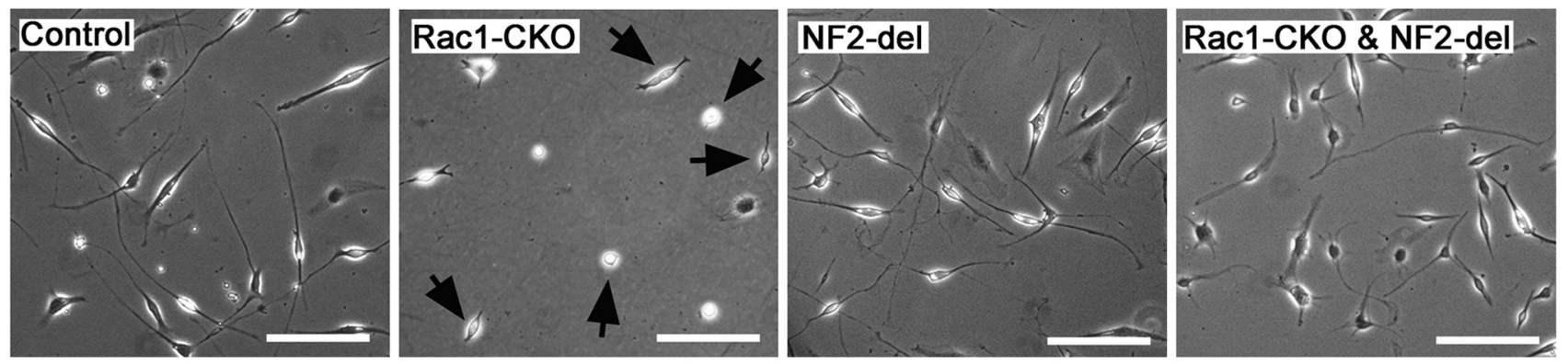

B
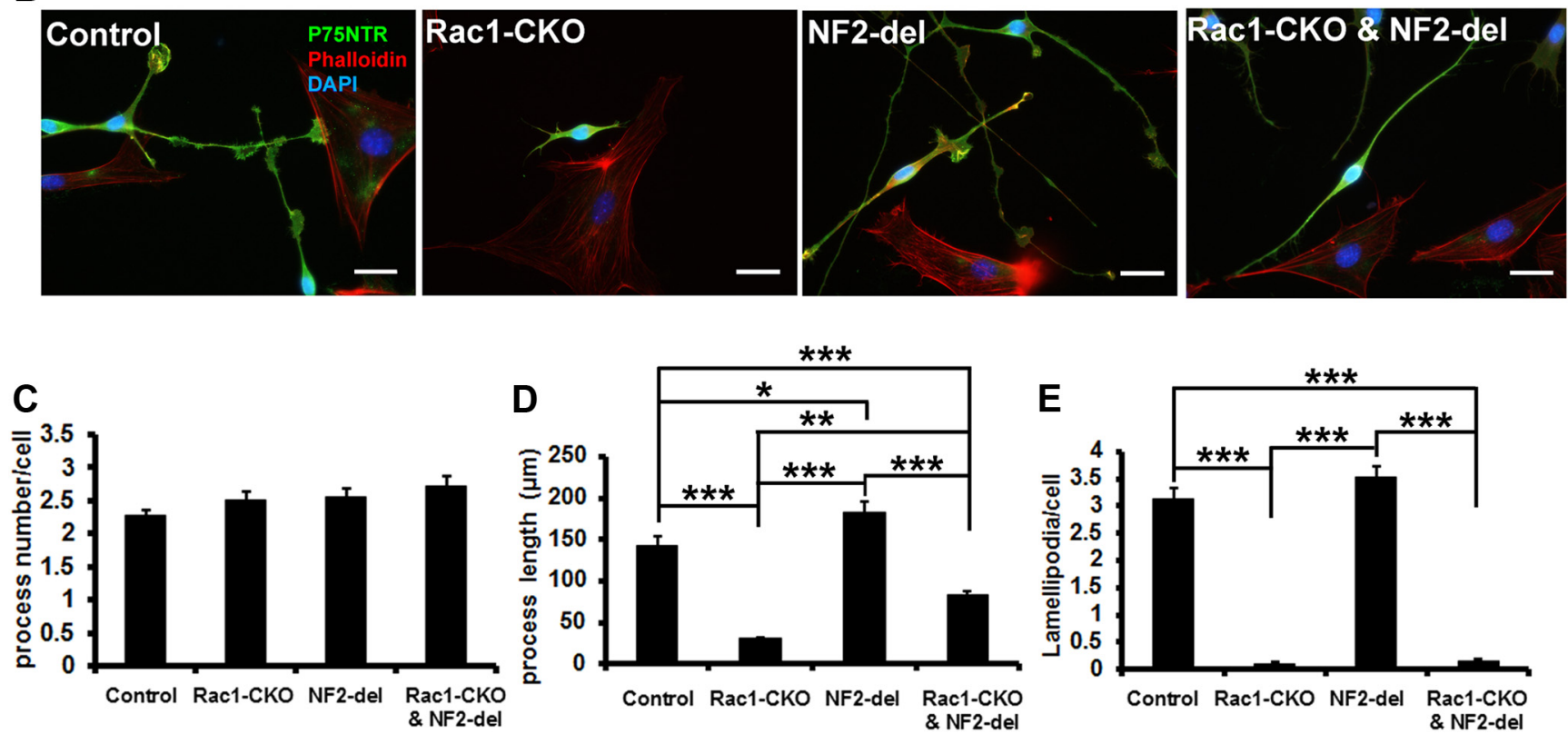

Figure 5. Impaired SC process elongation in Rac1-CKO SC is rescued by NF2/merlin mutation. A, SC cultures from control, Rac1-CKO, NF2-del, and Rac1-CK0\&NF2-del sciatic nerves are shown. SC process length in Rac1-CKO culture (arrows) is much shorter than that in wild-type culture. B, SCs cultured from P30 control, Rac1-CKO, NF2-del, and Rac1-CKO\&NF2-del sciatic nerves were immunostained using P75NTR (an SC marker, green) and phalloidin (F-actin cytoskeleton, red). Nuclei were visualized by DAPI (blue). Rac1-CKOSCs, but not Rac1-CK0\&NF2-del SCS, have short processes. C, There is no significant change of SC process numbers per cell in Rac1-CKO or Rac1-CKO\&NF2-del cultures. D, The average SC process length is significantly decreased in Rac1-CKO SCS. Process length in Rac1-CKO\&NF2-del SCs is increased compared with Rac1-CKOSCS. E, Lamellipodia numbers per cell are significantly decreased in Rac1-CKOSCs and in Rac1-CKO\&NF2-del SCS. For $C-E, n>50$ cells from 3 independent experiments per genotype. ${ }^{*} p<0.05$, ${ }^{* *} p<0.01,{ }^{* * *} p<0.001$ by ANOVA statistical analysis, followed by Tukey's test. Error bars indicate \pm SEM. Scale bars: $A, 100 \mu \mathrm{m} ; \boldsymbol{B}, 25 \mu \mathrm{m}$.

observation that NF2/merlin functions in Rac1-mediated myelination in vivo.

Reduced E-cadherin expression in Rac1-CKO SCs is rescued by NF2/merlin mutant or elevation of cAMP

$\mathrm{NF} 2 /$ merlin is thought to stabilize cadherin-containing adherens junctions (Lallemand et al., 2003). E-cadherin is an important

\section{$\leftarrow$}

(Figure legend continued.) in Rac1-CKO sciatic nerves in vivo remained in Rac1-CKO\&NF2-del sciatic nerves (arrowheads). C, The number of myelinated axons is significantly increased in Rac1-CKO\&NF2-del mice compared with Rac1-CKO mice. $\boldsymbol{D}$, The number of axons in one-to-one SC-axon profile without myelination is decreased in Rac1-CKO\&NF2-del mice versus Rac1-CKO mice. $\boldsymbol{E}$, Western blot analysis of Pmp22, a peripheral myelin protein, in control, Rac1-CKO, NF2-del, and Rac1-CKO\&NF2-del sciatic nerves. Quantification from three independent experiments shows Pmp22 expression was significantly decreased in Rac1-CKO sciatic nerves. Reduced Pmp22 expression in Rac1-CK0 sciatic nerves was rescued in Rac1-CK0\&NF2-del sciatic nerves. $\boldsymbol{F}$, EM analysis of control (a), Rac1-CKO (b), NF2-del (c), and Rac1-CKO\&NF2-del (d) nerves. Small axons are normally segregated by SCs and form Remak bundles in Rac1-CKO nerves and Rac1-CKO\&NF2-del nerves, although no myelin sheath forms in Rac1-CKO nerves. For $\boldsymbol{C}$ and $\boldsymbol{D}, n \geq 25$ fields from at least 5 animals per genotype were analyzed. ${ }^{*} p<0.05$, ${ }^{* *} p<0.01,{ }^{* * *} p<0.001$ by ANOVA statistical analysis, followed by Tukey's test. Error bars indicate \pm SEM. Scale bars: $\boldsymbol{B}$, top row, $\boldsymbol{F}, 5 \mu \mathrm{m} ; \boldsymbol{B}$, bottom row, $2 \mu \mathrm{m}$. constituent of adherens junctions and plays a key role at cell-cell junctions, although it is not itself necessary for myelination (Young et al., 2002). We used Western blot analysis to test E-cadherin expression in sciatic nerves. E-cadherin expression was significantly decreased in the absence of Racl (Fig. 6A,B). Decreased E-cadherin expression in Rac1-CKO sciatic nerves was rescued in Rac1-CKO\&NF2-del sciatic nerves (Fig. 6A,B). Because cAMP is critical for E-cadherin expression in postnatal SCs (Crawford et al., 2008), we tested whether elevation of cAMP levels could restore E-cadherin expression in Rac1-CKO nerves. Forskolin was used to elevate cAMP levels in wild-type or Rac1$\mathrm{CKO}$ nerve segments in vitro. Forskolin treatment increased both E-cadherin expression and phosphorylation of merlin (Fig. $6 C, D)$. These results suggest that Racl regulates E-cadherin expression in SCs through NF2/merlin and/or cAMP signaling.

The myelination defect in Rac1-CKO mice is rescued by cAMP elevation in vivo

To better define relationships among Rac1, cAMP, and NF2/ merlin, we measured cAMP levels in sciatic nerves of control, Rac1-CKO, NF2-del, and Rac1-CKO\&NF2-del mice. cAMP lev- 
A

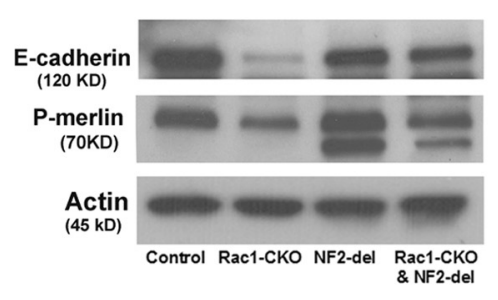

C

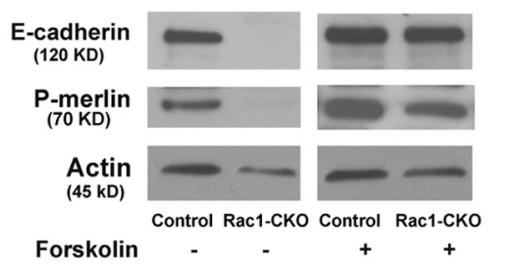

E

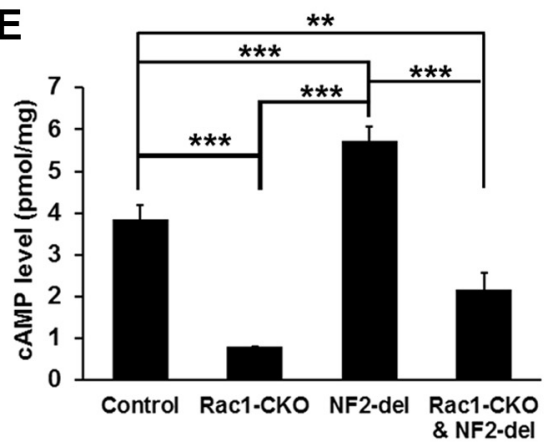

B

D
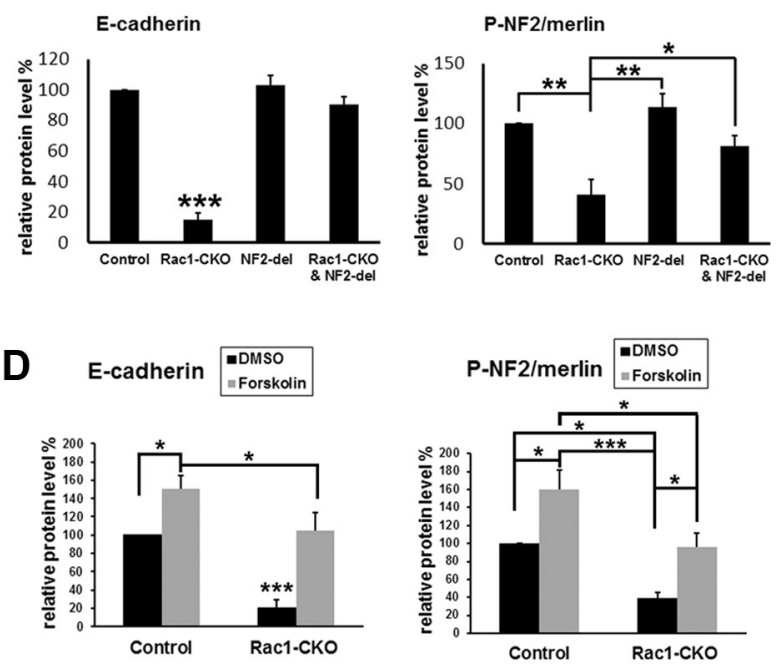

$\mathbf{F}$

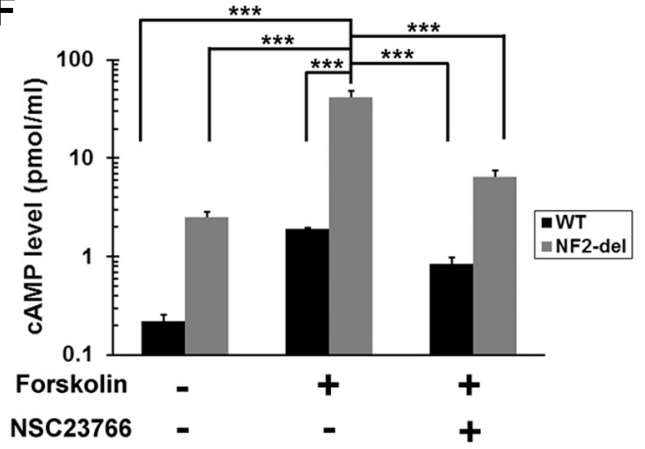

Figure 6. Rac1 and NF2/merlin regulate CAMP in SCs. A, Western blots analysis of E-cadherin and P-NF2/merlin in control, Rac1-CKO, NF2-del, and Rac1-CKO\&NF2-del sciatic nerves. $\boldsymbol{B}$, Quantification from four independent experiments shows that E-cadherin expression and NF2/merlin phosphorylation were significantly decreased in Rac1-CKO sciatic nerves. Reduced E-cadherin expression in Rac1-CKO sciatic nerves was rescued in Rac1-CKO\&NF2-del sciatic nerves. C, Forskolin was added in control or Rac1-CKO nerve grafts in vitro for $48 \mathrm{~h}$ and then E-cadherin expression and $\mathrm{NF2}$ /merlin phosphorylation were detected by Western blots. $\boldsymbol{D}$, Quantification from three independent experiments shows that decreased E-cadherin expression and NF2/merlin phosphorylation in Rac1-CKO nerve grafts was rescued by forskolin treatment in vitro. E, CAMP levels were measured in sciatic nerves of control $(n=8)$, Rac1-CKO $(n=8)$, NF2-del ( $n=7)$, and Rac1-CKO\&NF2-del $(n=6)$ mice. cAMP levels in Rac1-CKO nerves are significant lower than in control nerves. CAMP levels in NF2-del nerves are significant higher than in control nerves. Decreased cAMP in Rac1-CKO nerves was restored in Rac1-CKO\&NF2-del nerves by $t$ test. $F$, cAMP levels in cultured wild-type $(n=3)$ or NF2-del $(n=3)$ SCs were measured before and after forskolin stimulation (30 min in serum-free medium). Both basal and forskolin-stimulated cAMP levels were increased in NF2-del SCs. The Rac1 specific inhibitor NSC23766 reduced forskolin-stimulated cAMP levels in cultured wild-type and NF2-del SCS. ${ }^{*} p<0.05,{ }^{* *} p<0.01,{ }^{* *} p<0.001$ by ANOVA, followed by Tukey's test. Error bars indicate \pm SEM.

els in Rac1-CKO nerves were significantly lower than those in control nerves, whereas cAMP levels in NF2-del nerves were significantly higher than those in control nerves (Fig. 6E). Importantly, compared with Rac1-CKO nerves, cAMP levels were increased in Rac1-CKO\&NF2-del nerves (Fig. 6E). The difference in cAMP levels between Rac1-CKO versus Rac1CKO\&NF2-del was not significant by ANOVA, followed by Tukey's analysis using multiple-group comparison with wildtype and NF2-del nerves. However, $t$ test in six independent samples shows that the difference in cAMP between Racl and Rac1-CKO\&NF2-del nerves is significant $(p<0.05)$. These results suggest that Rac1 regulates cAMP at least in part through NF2/merlin signaling.

To confirm a link between Rac1, cAMP, and NF2/merlin, we used a Rac1-specific inhibitor, NSC23766 (Gao et al., 2004), in cultured wild-type or NF2-del SCs in vitro. Both basal and stimulated levels of cAMP were increased in NF2-del SCs compared with wild-type SCs (Fig. 6F). Rac1 inhibition by NSC23766 reduced forskolin-stimulated cAMP levels in cultured wild-type and NF2-del SCs. These results confirm that Rac1 and NF2/merlin regulate cAMP in SCs.
To test whether low cAMP prevents myelination in Rac1 mutants in vivo, we used the phosphodiesterase inhibitor rolipram to elevate cAMP levels in Rac1-CKO mice in vivo. A significant increase in myelinated axons was observed in Rac1-CKO mice after 6-8 weeks daily treatment with rolipram (Fig. $7 A, B$ ). These results demonstrate that elevating cAMP in Racl mutants is sufficient to enable SC myelination in vivo. However, SC protrusions remained in Rac1-CKO nerves after rolipram treatment (Fig. $7 C$, arrow). In addition, abnormal folding of SC myelin sheath (Fig. $7 C$, arrowheads) was occasionally observed in Rac1-CKO nerves after rolipram treatment. Thus, the SC myelination defects in Rac1-CKO mice are partially rescued by NF2-del mutant or rolipram treatment, both of which increase cAMP in vivo.

\section{Discussion}

We identified a novel pathway in which Racl promotes SC myelination through cAMP signaling and NF2/merlin. Our data in Rac1-CKO mice showed that Racl plays an important role in SC myelination, because SCs did not form myelin sheaths in the absence of Racl. Rac1-CKO SCs had decreased NF2/merlin phosphorylation. Rac1 regulates SC myelination through NF2/merlin, because 
A
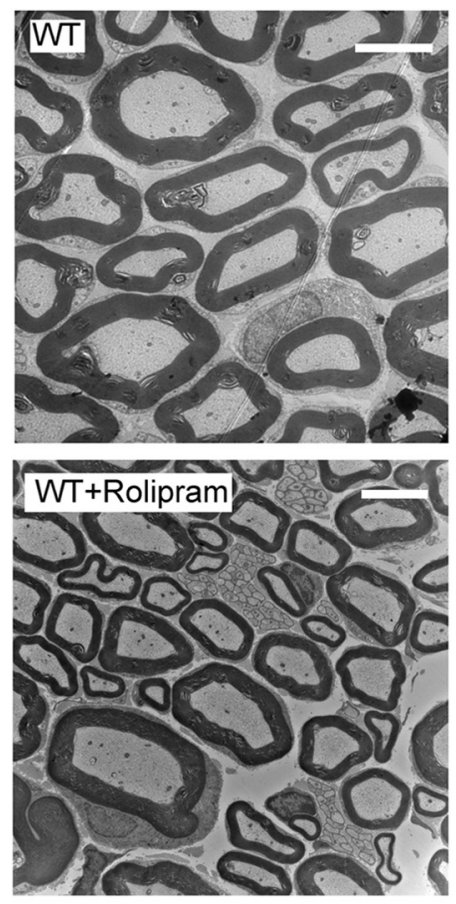

B

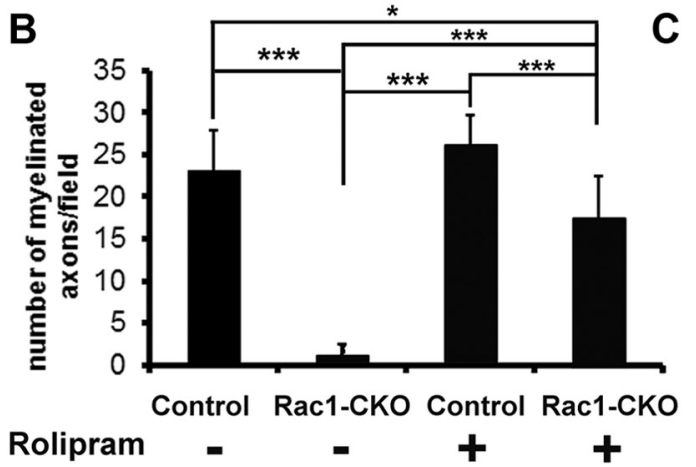

Figure 7. Myelination defects in Rac1-CKO mice were rescued by cAMP elevation. $A$, EM analysis of control, Rac1-CKO sciatic nerve cross-sections with $6-8$ weeks daily intraperitoneal injection of rolipram. $\boldsymbol{B}$, The number of myelinated axons is significant increase in Rac1-CKO sciatic nerve after rolipram treatment. C, Abnormal SC protusion remains in Rac1-CKO SC after rolipram treatment (arrow). Occasionally, abnormal folding of $\mathrm{SC}$ myelin sheath (arrowheads) was observed in Rac1-CKO nerves after rolipram treatment. For $\boldsymbol{B}, n \geq 15$ fields from 6 animals per genotype with rolipram treatment were analyzed. ${ }^{*} p<0.05,{ }^{* * *} p<$ 0.001 by ANOVA, followed by Tukey's test. Error bars indicate \pm SEM. Scale bars: $A, 5 \mu \mathrm{m} ; C, 1 \mu \mathrm{m}$.

the myelin deficits in Rac1-CKO SCs were rescued by loss of NF2/ merlin function. Decreased NF2/merlin phosphorylation in Rac1CKO nerves also correlated with decreased cAMP and NF2/merlin mutant nerves had increased cAMP levels. Acute elevation of cAMP in vitro using forskolin increased NF2/merlin phosphorylation. In addition, using rolipram to elevate cAMP in vivo rescued the myelin deficiency in Rac1-CKO mice. The results of this study are summarized in Figure 8.

A previous study described a delay in radial sorting at developmental stages (E17.5 to P24) after Rac1 knock-out (Benninger et al., 2007; Nodari et al., 2007). Our study at later time points (P0-P120) support a major role for Rac1 in SC myelination. We found that myelin sheaths do not form in the Rac1 mutant mice at P15, P30, P60, and P120, although most SCs establish one-to-one relationship with large axons. Thus, we conclude that Racl is required at the initiation of SC myelination, after axonal sorting is complete. These differences in phenotypes may be attributable to strain background differences and/or be related to the difference in gene targeting strategies (Benitah et al., 2005; Cappello et al., 2006; Chen et al., 2006; Chrostek et al., 2006; Castilho et al., 2007). Consistent with our results that Rac1 is critical for SC myelination, a recent study reported that active Rac1 is localized to the axon-glial interface in SCs by Par3 and that polarization of Racl activation is critical for myelination (Tep et al., 2012).

Unmyelinated large axons in sciatic nerves of Rac1-CKO mice became myelinated in Rac1-CKO\&NF2-del double mutants. The role of NF2/merlin in cellular differentiation is poorly studied. Indeed, a minor role for NF2/merlin in SC differentiation was proposed, yet contacts between SCs and axons at paranodes regions were altered in NF2-del mice (Denisenko et al., 2008). We confirmed the absence of significant defects in myelin internodes at P30-P180 in NF2-del mutant mice. Our data show that NF2/ merlin plays a critical role downstream of Racl in SC differentiation in vivo, which is revealed by the absence of Rac1.

Our in vitro analyses using SCs with genetic loss of Rac1 confirm data of Benninger et al. (2007). Both studies show that Rac1 null cells have short processes, indicating that Racl normally promotes SC processes elongation. In contrast, rat SCs expressing dominant-negative Rac1 extended abnormally long bipolar processes in vitro (Thaxton et al., 2011). The difference between using the dominantnegative Rac1 and the genetic loss of Rac1 in SC process elongation remains to be analyzed. Comparison of SC morphology in primary cultures provided compelling additional evidence that Racl function is NF2/merlin dependent, because short processes in Rac1-CKO SCs were rescued in Rac1-CKO\&NF2-del SCs.

Myelin sheath thickness in the Rac1CKO\&NF2-del mice was not completely rescued to the myelin thickness characteristic of control mice and resembles the thin myelin seen after remyelination. It is also likely that NF2/merlin is not the only Racl downstream effector that contributes to SC function, especially because Rac1-CKO\&NF2del cultured SCs were partially rescued in process length. The irregular SC protrusions in Rac1-CKO sciatic nerves and the lamellipodia defects in Rac1-CKO SCs were unaffected by NF2/ merlin function.

SC myelination requires CAMP. For example, addition of cAMP to $\mathrm{SC}$ cultures increases the expression of myelin genes and proteins (Sobue et al., 1986), the G-protein-coupled receptor GPR126 is essential for SC myelination in vivo (Monk et al., 2009), and cAMPdependent phosphorylation of the transcription factor nuclear factor- $\kappa \mathrm{B}$ is required for myelin formation (Yoon et al., 2008). Our results provide in vitro and in vivo evidence for a novel pathway in which Racl promotes myelination through cAMP signaling and $\mathrm{NF} 2 /$ merlin. Upstream activators of Rac1/cAMP signaling in this myelination pathway remain to be identified. Racl has been 
linked to laminins and $\beta 1$ integrins in SC myelination (Nodari et al., 2007; Yu et al., 2009). Intriguingly, integrins activate cAMP signaling through $\mathrm{G} \alpha_{\mathrm{s}}$ in endothelial cells (Alenghat et al., 2009). It is possible that integrin, signaling through $\mathrm{G} \alpha$ s and Rac1, activates cAMP to control SC myelination.

We found that PAK is a major effector of Rac1 in SCs, as when Rac1 is lost P-PAK at Thr423 (PAK1)/Thr402 (PAK2) is absent. Consistent with absence of P-PAK in Rac1-CKO SCs, we observed decreased NF2/merlin phosphorylation at Ser518, a site known to be a substrate of PAK. Protein kinase A (PKA) can also phosphorylate NF2/merlin on Ser518 (Laulajainen et al., 2008), and the reduction in CAMP in Rac1-CKO SCs is predicted to lead to decreased PKA activity, which may contribute to reduced merlin phosphorylation. Consistent with PKA acting upstream of merlin, forskolin increased NF2/merlin phosphorylation. However, cAMP levels also increased in NF2del mutants in vitro and in vivo, suggesting a feedback mechanism. In this sense, NF2/merlin may be upstream of cAMP. It is notable that a similar feedback loop has been described between Rac, PAK, and merlin (Kissil et al., 2003).

In normal nerve, Rac-GTP is predicted to phosphorylate PAK; PAK would phosphorylate merlin, possibly increasing cAMP and promoting myelination. In the absence of Rac1, the dephosphorylated NF2/merlin correlates with decreased cAMP, preventing myelination. Nonphosphorylated NF2/merlin is increasingly believed to have critical functions, for example, in cell growth (Li et al., 2010; Sher et al., 2012). Intriguingly, both mutation in PKA and mutation in NF2, correlate with SC tumorigenesis (Jones et al., 2008). It will be of interest to study whether cAMP levels are changed in NF2/merlin-deficient SC tumors.

In summary, our study provided in vitro and in vivo evidence supporting a novel pathway in which Racl regulates SC myelination through NF2/merlin and cAMP. We have also established a functional link between NF2/merlin, cAMP, and Rac1 in SC myelination. Myelin defects in the PNS are associated with demyelinating diseases as well as tumors. Therefore, these observations may be relevant to SC development, nerve pathology, and tumorigenesis.

\section{References}

Alenghat FJ, Tytell JD, Thodeti CK, Derrien A, Ingber DE (2009) Mechanical control of cAMP signaling through integrins is mediated by the heterotrimeric Galphas protein. J Cell Biochem 106:529-538. CrossRef Medline

Arthur-Farraj P, Wanek K, Hantke J, Davis CM, Jayakar A, Parkinson DB, Mirsky R, Jessen KR (2011) Mouse Schwann cells need both NRG1 and cyclic AMP to myelinate. Glia 59:720-733. CrossRef Medline

Benitah SA, Frye M, Glogauer M, Watt FM (2005) Stem cell depletion through epidermal deletion of Rac1. Science 309:933-935. CrossRef Medline

Benninger Y, Thurnherr T, Pereira JA, Krause S, Wu X, Chrostek-Grashoff A, Herzog D, Nave KA, Franklin RJ, Meijer D, Brakebusch C, Suter U, Relvas JB (2007) Essential and distinct roles for cdc42 and racl in the regulation of Schwann cell biology during peripheral nervous system development. J Cell Biol 177:1051-1061. CrossRef Medline

Bhatheja K, Field J (2006) Schwann cells: origins and role in axonal maintenance and regeneration. Int J Biochem Cell Biol 38:1995-1999. CrossRef Medline
Cappello S, Attardo A, Wu X, Iwasato T, Itohara S, Wilsch-Bräuninger M, Eilken HM, Rieger MA, Schroeder TT, Huttner WB, Brakebusch C, Götz M (2006) The Rho-GTPase cdc42 regulates neural progenitor fate at the apical surface. Nat Neurosci 9:1099-1107. CrossRef Medline

Castilho RM, Squarize CH, Patel V, Millar SE, Zheng Y, Molinolo A, Gutkind JS (2007) Requirement of Racl distinguishes follicular from interfollicular epithelial stem cells. Oncogene 26:5078-5085. CrossRef Medline

Chen L, Liao G, Yang L, Campbell K, Nakafuku M, Kuan CY, Zheng Y (2006) Cdc42 deficiency causes Sonic hedgehog-independent holoprosencephaly. Proc Natl Acad Sci U S A 103:16520-16525. CrossRef Medline

Chen L, Zhang JJ, Huang XY (2008) cAMP inhibits cell migration by interfering with Rac-induced lamellipodium formation. J Biol Chem 283: 13799-13805. CrossRef Medline

Chrostek A, Wu X, Quondamatteo F, Hu R, Sanecka A, Niemann C, Langbein L, Haase I, Brakebusch C (2006) Racl is crucial for hair follicle integrity but is not essential for maintenance of the epidermis. Mol Cell Biol 26: 6957-6970. CrossRef Medline

Crawford AT, Desai D, Gokina P, Basak S, Kim HA (2008) E-cadherin expression in postnatal Schwann cells is regulated by the cAMP-dependent protein kinase a pathway. Glia 56:1637-1647. CrossRef Medline

Curto M, McClatchey AI (2008) Nf2/Merlin: a coordinator of receptor signalling and intercellular contact. Br J Cancer 98:256-262. CrossRef Medline

Denisenko N, Cifuentes-Diaz C, Irinopoulou T, Carnaud M, Benoit E, NiwaKawakita M, Chareyre F, Giovannini M, Girault JA, Goutebroze L (2008) Tumor suppressor schwannomin/merlin is critical for the organization of Schwann cell contacts in peripheral nerves. J Neurosci 28:10472-10481. CrossRef Medline

Fannon AM, Sherman DL, Ilyina-Gragerova G, Brophy PJ, Friedrich VL Jr, Colman DR (1995) Novel E-cadherin-mediated adhesion in peripheral nerve: Schwann cell architecture is stabilized by autotypic adherens junctions. J Cell Biol 129:189-202. CrossRef Medline

Flaiz C, Ammoun S, Biebl A, Hanemann CO (2009) Altered adhesive structures and their relation to RhoGTPase activation in merlin-deficient Schwannoma. Brain Pathol 19:27-38. CrossRef Medline

Gao Y, Dickerson JB, Guo F, Zheng J, Zheng Y (2004) Rational design and characterization of a Rac GTPase-specific small molecule inhibitor. Proc Natl Acad Sci U S A 101:7618-7623. CrossRef Medline

Giovannini M, Robanus-Maandag E, Niwa-Kawakita M, van der Valk M, Woodruff JM, Goutebroze L, Mérel P, Berns A, Thomas G (1999) Schwann cell hyperplasia and tumors in transgenic mice expressing a naturally occurring mutant NF2 protein. Genes Dev 13:978-986. CrossRef Medline

Giovannini M, Robanus-Maandag E, van der Valk M, Niwa-Kawakita M, Abramowski V, Goutebroze L, Woodruff JM, Berns A, Thomas G (2000) 
Conditional biallelic Nf2 mutation in the mouse promotes manifestations of human neurofibromatosis type 2. Genes Dev 14:1617-1630. Medline

Guo F, Cancelas JA, Hildeman D, Williams DA, Zheng Y (2008) Rac GTPase isoforms Rac1 and Rac2 play a redundant and crucial role in T-cell development. Blood 112:1767-1775. CrossRef Medline

Jaegle M, Ghazvini M, Mandemakers W, Piirsoo M, Driegen S, Levavasseur F, Raghoenath S, Grosveld F, Meijer D (2003) The POU proteins Brn-2 and Oct-6 share important functions in Schwann cell development. Genes Dev 17:1380-1391. CrossRef Medline

Jessen KR, Mirsky R (2005) The origin and development of glial cells in peripheral nerves. Nat Rev Neurosci 6:671-682. CrossRef Medline

Jones GN, Tep C, Towns WH 2nd, Mihai G, Tonks ID, Kay GF, Schmalbrock PM, Stemmer-Rachamimov AO, Yoon SO, Kirschner LS (2008) Tissuespecific ablation of Prkarla causes schwannomas by suppressing neurofibromatosis protein production. Neoplasia 10:1213-1221. CrossRef Medline

Kaempchen K, Mielke K, Utermark T, Langmesser S, Hanemann CO (2003) Upregulation of the Rac1/JNK signaling pathway in primary human schwannoma cells. Hum Mol Genet 12:1211-1221. CrossRef Medline

Kissil JL, Wilker EW, Johnson KC, Eckman MS, Yaffe MB, Jacks T Merlin (2003) The product of the Nf2 tumor suppressor gene, is an inhibitor of the p21-activated kinase, Pak1. Mol Cell 12:841-849. CrossRef Medline

Lallemand D, Curto M, Saotome I, Giovannini M, McClatchey AI (2003) NF2 deficiency promotes tumorigenesis and metastasis by destabilizing adherens junctions. Genes Dev 17:1090-1100. CrossRef Medline

Laulajainen M, Muranen T, Carpén O, Grönholm M (2008) Protein kinase A-mediated phosphorylation of the NF2 tumor suppressor protein merlin at serine 10 affects the actin cytoskeleton. Oncogene 27:3233-3243. CrossRef Medline

Li W, You L, Cooper J, Schiavon G, Pepe-Caprio A, Zhou L, Ishii R, Giovannini M, Hanemann CO, Long SB, Erdjument-Bromage H, Zhou P, Tempst P, Giancotti FG (2010) Merlin/NF2 suppresses tumorigenesis by inhibiting the E3 ubiquitin ligase CRL4(DCAF1) in the nucleus. Cell 140:477-490. CrossRef Medline

Menichella DM, Arroyo EJ, Awatramani R, Xu T, Baron P, Vallat JM, Balsamo J, Lilien J, Scarlato G, Kamholz J, Scherer SS, Shy ME (2001) Protein zero is necessary for E-cadherin-mediated adherens junction formation in Schwann cells. Mol Cell Neurosci 18:606-618. CrossRef Medline

Monk KR, Naylor SG, Glenn TD, Mercurio S, Perlin JR, Dominguez C, Moens CB, Talbot WS (2009) A G protein-coupled receptor is essential for Schwann cells to initiate myelination. Science 325:1402-1405. CrossRef Medline

Nakai Y, Zheng Y, MacCollin M, Ratner N (2006) Temporal control of Rac in Schwann cell-axon interaction is disrupted in NF2-mutant schwannoma cells. J Neurosci 26:3390-3395. CrossRef Medline

Nodari A, Zambroni D, Quattrini A, Court FA, D'Urso A, Recchia A, Tybulewicz VL, Wrabetz L, Feltri ML (2007) Betal integrin activates Rac1 in Schwann cells to generate radial lamellae during axonal sorting and myelination. J Cell Biol 177:1063-1075. CrossRef Medline

Perrin-Tricaud C, Rutishauser U, Tricaud N (2007) P120 catenin is required for thickening of Schwann cell myelin. Mol Cell Neurosci 35:120129. CrossRef Medline

Roche PH, Bouvier C, Chinot O, Figarella-Branger D (2008) Genesis and biology of vestibular schwannomas. Prog Neurol Surg 21:24-31. CrossRef Medline

Rong R, Surace EI, Haipek CA, Gutmann DH, Ye K (2004) Serine 518 phosphorylation modulates merlin intramolecular association and binding to critical effectors important for NF2 growth suppression. Oncogene 23: 8447-8454. CrossRef Medline
Scoles DR (2008) The merlin interacting proteins reveal multiple targets for NF2 therapy. Biochim Biophys Acta 1785:32-54. CrossRef Medline

Sher I, Hanemann CO, Karplus PA, Bretscher A (2012) The tumor suppressor merlin controls growth in its open state, and phosphorylation converts it to a less-active more-closed state. Dev Cell 22:703-705. CrossRef Medline

Sobue G, Shuman S, Pleasure D (1986) Schwann cell responses to cyclic AMP: proliferation, change in shape, and appearance of surface galactocerebroside. Brain Res 362:23-32. CrossRef Medline

Tep C, Kim ML, Opincariu LI, Limpert AS, Chan JR, Appel B, Carter BD, Yoon SO (2012) Brain-derived neurotrophic factor (BDNF) induces polarized signaling of small GTPase (Racl) protein at the onset of Schwann cell myelination through partitioning-defective 3 (Par3) protein. J Biol Chem 287:1600-1608. CrossRef Medline

Thaxton C, Bott M, Walker B, Sparrow NA, Lambert S, Fernandez-Valle C (2011) Schwannomin/merlin promotes Schwann cell elongation and influences myelin segment length. Mol Cell Neurosci 47:1-9. CrossRef Medline

Wanner IB, Guerra NK, Mahoney J, Kumar A, Wood PM, Mirsky R, Jessen KR (2006) Role of N-cadherin in Schwann cell precursors of growing nerves. Glia 54:439-459. CrossRef Medline

Williams JP, Wu J, Johansson G, Rizvi TA, Miller SC, Geiger H, Malik P, Li W, Mukouyama YS, Cancelas JA, Ratner N (2008) Nf1 mutation expands an EGFR-dependent peripheral nerve progenitor that confers neurofibroma tumorigenic potential. Cell Stem Cell 3:658-669. CrossRef Medline

Wu J, Williams JP, Rizvi TA, Kordich JJ, Witte D, Meijer D, StemmerRachamimov AO, Cancelas JA, Ratner N (2008) Plexiform and dermal neurofibromas and pigmentation are caused by Nf1 loss in desert hedgehog-expressing cells. Cancer Cell 13:105-116. CrossRef Medline

Xiao GH, Beeser A, Chernoff J, Testa JR (2002) p21-activated kinase links Rac/Cdc42 signaling to merlin. J Biol Chem 277:883-886. CrossRef Medline

Yamauchi J, Miyamoto Y, Tanoue A, Shooter EM, Chan JR (2005) Ras activation of a Racl exchange factor, Tiam1, mediates neurotrophin-3induced Schwann cell migration. Proc Natl Acad Sci U S A 102:1488914894. CrossRef Medline

Yang L, Wang L, Zheng Y (2006) Gene targeting of Cdc42 and Cdc42GAP affirms the critical involvement of Cdc42 in filopodia induction, directed migration, and proliferation in primary mouse embryonic fibroblasts. Mol Biol Cell 17:4675-4685. CrossRef Medline

Yang L, Wang L, Geiger H, Cancelas JA, Mo J, Zheng Y (2007) Rho GTPase Cdc42 coordinates hematopoietic stem cell quiescence and niche interaction in the bone marrow. Proc Natl Acad Sci U S A 104:5091-5096. CrossRef Medline

Ye K (2007) Phosphorylation of merlin regulates its stability and tumor suppressive activity. Cell Adh Migr 1:196-198. CrossRef Medline

Yi C, Wilker EW, Yaffe MB, Stemmer-Rachamimov A, Kissil JL (2008) Validation of the p21-activated kinases as targets for inhibition in neurofibromatosis type 2. Cancer Res 68:7932-7937. CrossRef Medline

Yoon C, Korade Z, Carter BD (2008) Protein kinase A-induced phosphorylation of the $\mathrm{p} 65$ subunit of nuclear factor- $\kappa \mathrm{B}$ promotes Schwann cell differentiation into a myelinating phenotype. J Neurosci 28:3738-3746. CrossRef Medline

Young P, Boussadia O, Berger P, Leone DP, Charnay P, Kemler R, Suter U (2002) E-cadherin is required for the correct formation of autotypic adherens junctions of the outer mesaxon but not for the integrity of myelinated fibers of peripheral nerves. Mol Cell Neurosci 21:341-351. CrossRef Medline

Yu WM, Chen ZL, North AJ, Strickland S (2009) Laminin is required for Schwann cell morphogenesis. J Cell Sci 122:929-936. CrossRef Medline 